\title{
The Integrated and Combined (I\&C) evaluation system to detect status and trends of the CONECOFOR Permanent Monitoring Plots
}

\author{
Marco FERRETTI \\ Dipartimento di Biologia Vegetale, Piazzale delle Cascine 28, 50144 Firenze, Italy \\ current address: LINNÆA ambiente s.r.1., Via G. Sirtori 37, I-50137 Firenze, Italy \\ e-mail:m.ferretti@linnaea.org
}

\begin{abstract}
CONECOFOR is the Italian program for the intensive monitoring of forest ecosystems sponsored by the Ministry for Agricultural and Forest Policy and the European Commission. It is based upon a series of investigations carried out on 20 (27 from 1999) plots located throughout Italy. The investigations collect data on various ecosystem compartments (soil, ground vegetation, trees, atmosphere) and processes (atmospheric inputs, tree nutrition and growth). A major benefit of intensive monitoring programs is the opportunity they provide to organize integrated studies aimed at understanding the driving forces acting at the ecosystem level. In Italy, the Integrated and Combined $(I \& C)$ evaluation system within the CONECOFOR program involves three major approaches: (i) the evaluation of risk status in relation to air pollution, (ii) the quantification of the ecosystem's status and changes, and (iii) the evaluation of the relationship between pressure and status indicators through time. The I\&C project involves scientists from many institutions; major emphasis is placed on the evaluation of data quality and precision. These are regarded as the basic steps in the whole project and a likely source of information about the suitability of the current sample sizes for providing a proper estimation of the parameters under consideration. The paper will provide information on the conceptual and methodological background of the $I \& C$ project
\end{abstract}

Key words: ecosystem monitoring, status, change, ozone, nitrogen

\section{INTRODUCTION}

Well-designed and properly implemented long-term monitoring programs are important in so far as they provide baseline data on natural resources, highlight changes, and permit the creation of a basis for long-term ecological research which is crucial to an understanding of the causes of changes (Bricker \& Ruggiero 1998; Innes 1998; Spellerberg 1994). For this reason, the intensive and integrated monitoring of forest ecosystems currently being implemented in Europe (Kleemola \& Forsius 2000; EC-UN/ECE 1998; Skjelvåle \& Ulstein 1998), and similar programs carried out in North America (e.g. Vaughan et al. 2001), offer major opportunities for field ecologists. However, the understanding of how forest ecosystems function, and of their response to environmental factors, is a complex matter that needs robust design for site selection and data collection, longterm, good quality data on carefully selected indicators and appropriate data analysis and evaluation systems (Elzinga et al. 2001; Legendre \& Legendre 1998). In these respects, while great care is generally devoted to identifying which measurements should be performed at the monitoring sites (a sort of "shopping list"), and which methods of measurement, much less attention is paid to design issues and data evaluation. For example, within the intensive monitoring of forest ecosystems in Europe established under the auspices of the Convention on Long-Range Transboundary Air Pollution (CLRTAP) and with the support of the European Union,
Expert Panels and working groups provide expertise for every investigation to be carried out. Unfortunately, despite their considerable importance (in strategic terms much greater than the individual investigations), no comparable effort has been devoted to design features and evaluation systems, which have not been subjected to the review of any Expert group. This is unfortunate for many reasons: (i) unclear design can lead to inconsistent criteria for site selection; (ii) inconsistency in site selection criteria may hamper the data evaluation; and (iii) suggested evaluation systems may either not cover the issues of concern or be inadequate to provide results at the level of individual countries, i.e. failing to provide policy relevant, robust information to decision makers (Ferretti 2000b). These are the reasons for which in 1998 the National Focal Centre (NFC) of Italy took the decision to develop a formal evaluation system to process and evaluate the data generated by the Italian intensive forest ecosystem monitoring program (whose Italian acronym is CONECOFOR) (Gruppo di Esperti CONECOFOR-I\&C, 1998). The first step was to establish a Task Force (TF) for the integrated and combined (I\&C) evaluation of intensive monitoring data which includes the team leaders of the various investigations carried out at the Permanent Monitoring Plots (PMPs) of the program. In this paper I will present an overview of concepts, definitions, methods and first outcomes of the I\&C evaluation system. The system is termed Integrated and Combined (I\&C) because it is an attempt (i) to integrate data on different indicators, col-

Paper prepared within the CONECOFOR programme, by the contract with the Ministry for Agriculture and Forestry Policy - National Forest Service, Italy. CONECOFOR is part of the Pan-European Level II Intensive Monitoring of Forest Ecosystem and is co-sponsored by the European Commission. 


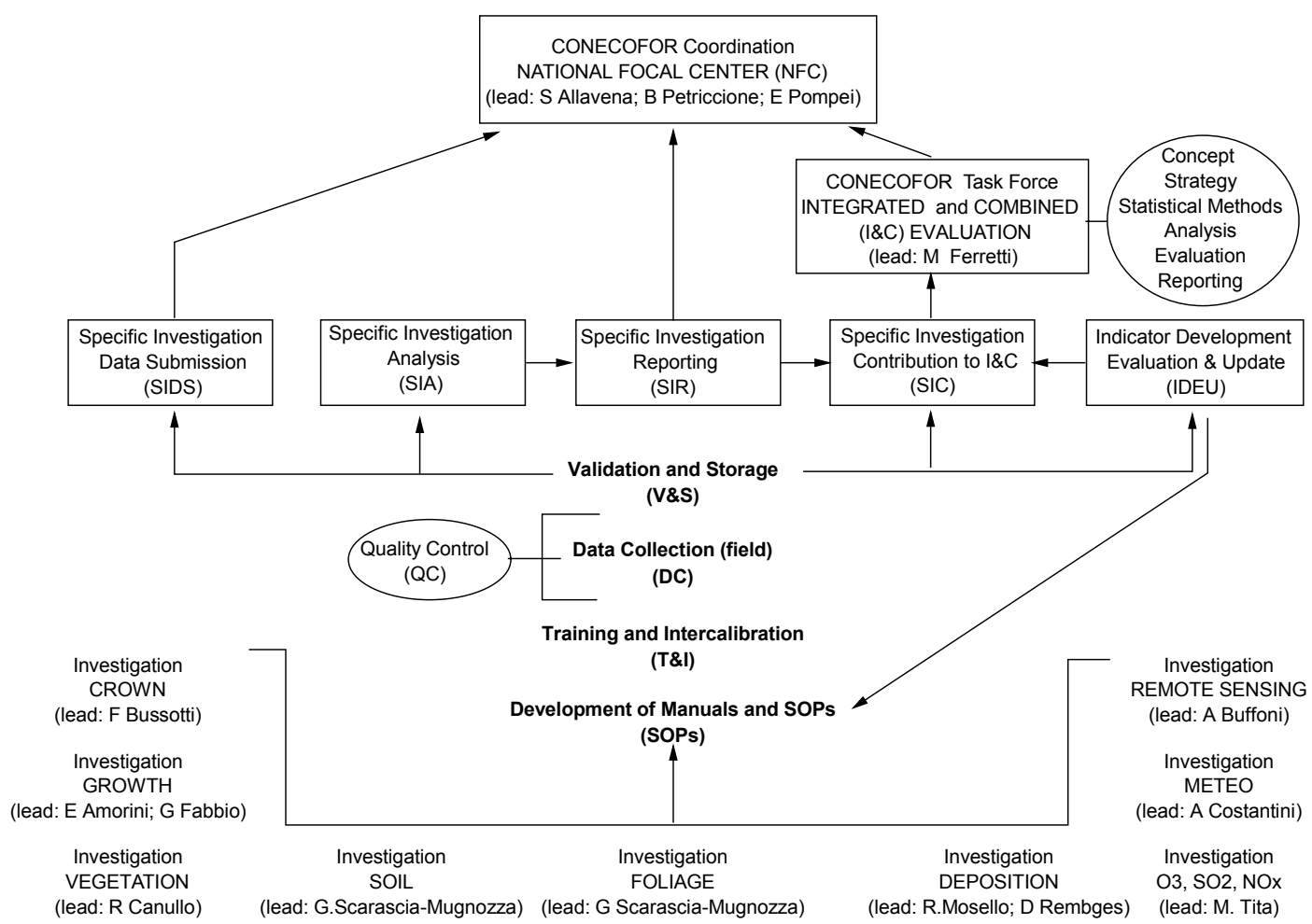

Fig. 1. The operational structure of the CONECOFOR program and the position of the I\&C evaluation system.

lected according to different sampling regimes and to different metrics; and (ii) to combine different evaluation perspectives in a cohesive and consistent evaluation system. Detailed information has been published elsewhere (e.g. Ferretti et al. 2000b; Ferretti 2000a) and this paper will make extensive reference to the previous ones.

\section{DEFINITION AND METHODS}

\subsection{Structure and position of $I \& C$ within the CONECOFOR program}

A general scheme is provided in figure 1. The I\&C is based on the work of existing Specific Investigation Teams (SITs), which remain responsible for the development of manuals and standard operating procedures, training and intercalibration, data collection, quality control, validation and storage of data, data submission, analysis, and reporting. SITs have the duty to provide a Specific Investigation Contribution (SIC) to the I\&C by a process of Indicator Development Evaluation and Update (IDEU), which can have a clear feedback on the standard operating procedures (SOPs). IDEU also plays an important role in the attempt to reduce the number of variables that can be used in the statistical analysis, thus improving the ratio between variables and cases.

\subsection{The I\&C evaluation system}

A full use of monitoring data needs different approaches. In this context, three kinds of analysis were identified to set up the I\&C evaluation system (Fig. 2): (i) risk analysis (RA), (ii) ecosystem status and changes analysis (S\&C), and (iii) nature of change analysis (NoC). Additional analyses will be explored in the future, with meta-analysis being of particular interest (e.g. Adams et al. 1997).

Risk analysis (RA) was suggested and designed taking into account the objective of the monitoring program. At the time the I\&C process was undertaken, air pollution was the major concern of the European regulation under which the whole monitoring program is funded. Therefore, risk analysis is aimed at understanding the actual risk of the target forest ecosystems in relation to air pollution (Ferretti et al. 2000b), i.e. to identify whether the actual or potential exposure to pollutants can be actually or potentially dangerous to the forest ecosystem concerned. The RA suggested within the I\&C has similarities with the Risk Assessment widely adopted and debated in the U.S. (Suter II 1990; Hunsaker et al. 1990; Power \& Adams 1997). Broadly, RA is defined as a process aimed at evaluating "the effects of an environmental change on a valued natural resource and interprets the significance of those effects in the light of uncertainties identified in each component of the assessment process" (Hunsaker et al. 1990). An important step of the process is to identify disturbance scenarios of concern. RA is based on the definition of three categories of potentially dangerous stressors and their possible action on the forest ecosystem, which can be evaluated considering various exposure and response 

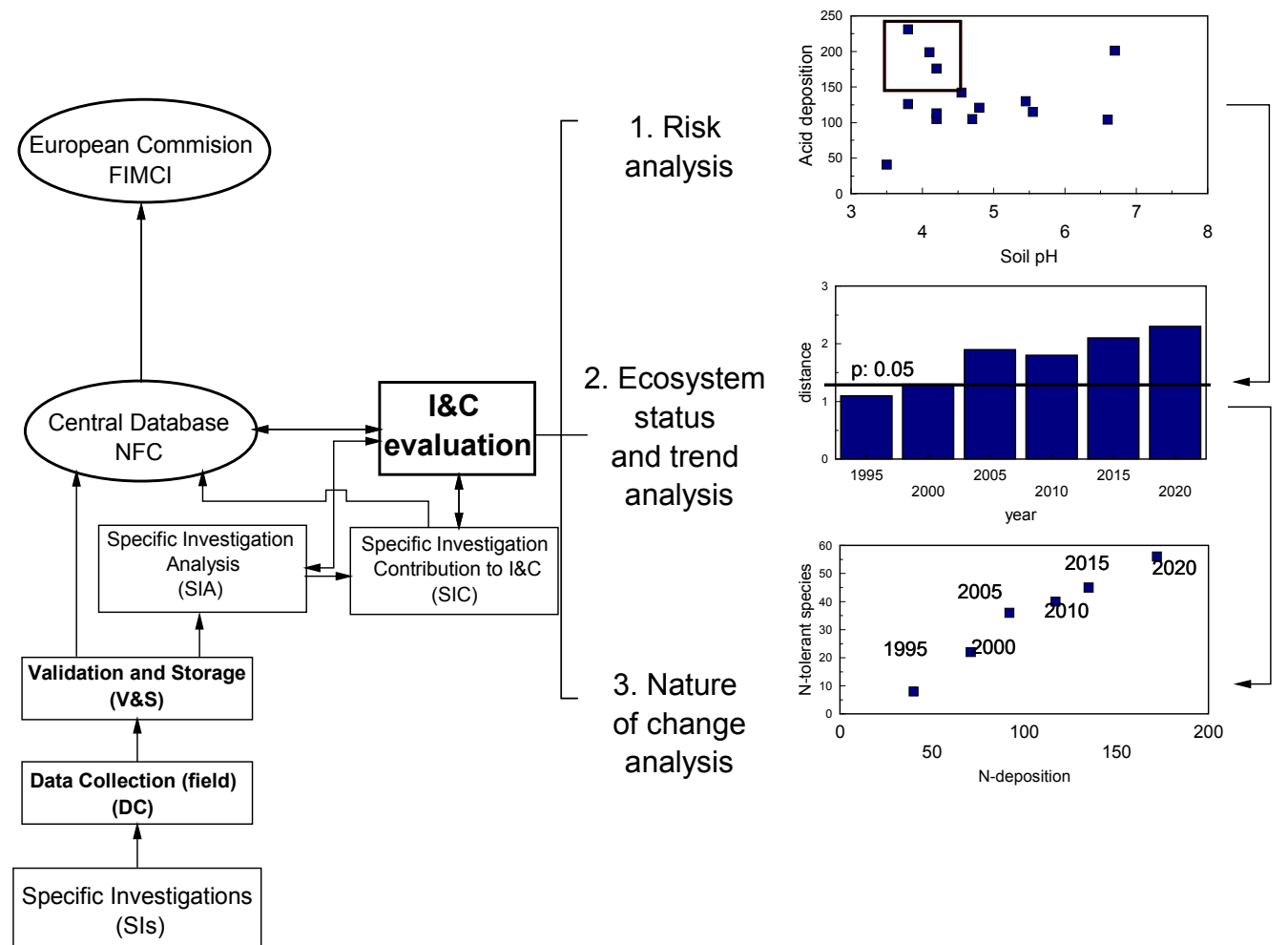

Fig. 2. The three analyses incorporated in the I\&C evaluation. See text for further explanations.

Tab. 1. Stressor, type of effect, expected actions (examples), exposure and response indicators adopted for Risk Analysis.

\begin{tabular}{|c|c|c|c|}
\hline Stressor/effect & Exposure indicator & Action on & Response indicator \\
\hline \multicolumn{4}{|l|}{$\mathrm{N}, \mathrm{H}^{+}$Deposition } \\
\hline Acute & precipitation chemistry & tree foliage, herbs & tree herbs \\
\hline Chronic & precipitation chemistry & ecosystem chemistry, productivity, dynamics & tree, soil, foliar, herbs \\
\hline \multicolumn{4}{|l|}{ Ozone } \\
\hline Acute & atmospheric chemistry & tree foliage, herbs & tree herbs \\
\hline Chronic & atmospheric chemistry & tree cond./growth/chemistry, vegetation dynamics & tree herbs \\
\hline \multicolumn{4}{|l|}{ Climate } \\
\hline Acute & atmospheric physics & tree cond./growth, herbs & tree herbs \\
\hline Chronic & atmospheric physics & tree cond./growth/phenology, vegetation dynamics & tree herbs \\
\hline
\end{tabular}

indicators and indices. Deposition of nitrogen and acidifying compounds, ozone concentrations and doses, as well as climate and weather fluctuations and changes, were identified as stressors of interest (Ferretti et al. 2000b). For each of them, both acute and chronic effects are considered (Tab. 1). These three issues of concern are closely related: for example, the effects of climatic changes and nitrogen fertilization can be difficult to separate and they can easily affect each other (e.g. Innes 1994; Chappelka \& Freer-Smith 1995). Table 1 provides an overview of the stressors, examples of their expected actions, indicators of exposure to the given stressors and indicators of response.

The aim of the status and change (S\&C) analysis is to quantify the ecosystem status and changes. This analysis will consider indicators and indices from as many investigations as possible, taking into account the existing differences occurring in sampling regimes and spatial allocations. This approach refers to a multidimensional scaling (MDS), a non-parametric multivariate analysis where individual communities/ecosystems are represented in an n-dimensional space: differences between communities/ecosystems are represented by the distance between the points, and changes in the status can be tracked by the trajectory of the point in such a space. This approach could be followed either in relation to an ecosystem's "mean status" over several years in order to collect baseline data to identify size and direction of change (Ferretti et al. 2000b), or in relation to a defined target condition or management objective (e.g. Lundquist \& Beatty 1999). With different methods, the approach of using a concept of distance between points in a multidimensional space was first developed for aquatic ecosystems (e.g. Field et al. 1982, quoted by 
Tab. 2. Time series needed to explore relationship between deposition (assumed as stressor) and various response entities. (a): in many plots, deposition data starts in 1998, while soil- and growth survey are always in 1995 and 1996, respectively.

\begin{tabular}{lccc}
\hline Stressor & Response & $\begin{array}{c}\text { Sampling regime of } \\
\text { response }\end{array}$ & $\begin{array}{c}\text { Time series needed to have 5 } \\
\text { points on a scatterplot }\end{array}$ \\
\hline Deposition & Soil & $10 \mathrm{y}$ & $1995-2035$ (a) \\
& Growth & $5 \mathrm{y}$ & $2000-2020(\mathrm{a})$ \\
& Ground vegetation & $1 \mathrm{y}$ & $1998-2003$ \\
& Foliage & $2 \mathrm{y}$ & $1999-2007$ \\
& Crown & $1 \mathrm{y}$ & $1998-2003$ \\
\hline
\end{tabular}

Tab. 3. Beech PMPs equipped with deposition collectors. Number of cases that will become available in the period 19982010. The number of variables that can be used in multivariate statistics (with $5: 1$ as casesvariables ratio) is reported in brackets.

\begin{tabular}{lccccccccc}
\hline Species & 1998 & 1999 & 2000 & 2001 & 2002 & 2003 & 2004 & 2005 \\
\hline Fagus sylvatica & $6(1)$ & $12(2)$ & $18(3)$ & $24(4)$ & $30(6)$ & $36(7)$ & $42(8)$ & $48(9)$ & $78(15)$ \\
Picea abies & 3 & $6(1)$ & $9(1)$ & $12(2)$ & $15(3)$ & $18(3)$ & $21(4)$ & $24(4)$ & $39(7)$ \\
Quercus cerris & 2 & 4 & $6(1)$ & $8(1)$ & $10(2)$ & $12(2)$ & $14(2)$ & $16(3)$ & $26(5)$ \\
Quercus ilex & 1 & 2 & 3 & 4 & $5(1)$ & $7(1)$ & $7(1)$ & $8(1)$ & $13(2)$ \\
\hline
\end{tabular}

Lundquist \& Beatty 1999; Johnson 1988) and then for forests (Lundquist \& Beatty 1999). As a first attempt, the approach adopted here is based on the use of the concept of Mahalanobis distance, while other statistical techniques (e.g. the kernel density estimation, Lundquist $\&$ Beatty 1999) will be tested in the future. The use of Mahalanobis distance is not new in forest condition monitoring: for example, Innes et al. (1996) used this method to identify trees with unusual foliage color. For the $\mathrm{S} \& \mathrm{C}$ analysis, the objective is to know the Mahalanobis distance of the ecosystem status $\mathrm{X}=\left(\mathrm{X}_{1}, \mathrm{X}_{2}, \ldots\right.$ $\left.X_{n}\right)$ at a given year, from a reference "mean status" computed over a time window (see below). The data generated by the $n$ indicators $X_{1}, X_{2}, \ldots X_{n}$ are used to identify the ecosystem status $Y_{1}, Y_{2}, \ldots Y_{k}$ at any given year $t_{1}, t_{2}, \ldots t_{k}$ and the distance between the status identified by the mean vector $\mu$ and each relevant year $Y_{1}$, $\mathrm{Y}_{2}, \ldots \mathrm{Y}_{\mathrm{k}}$ is then computed. As the time series increases, subsequent data are added to the model, thus strengthening the value of the mean status for those variables subjected to high short-term random fluctuation. With this approach, anomalous ecosystem status in a time series can be identified at the analytical stage by further statistical analysis of the distance values. Details are given by Ferretti et al. (2000c).

While RA and S\&C are aimed at identifying risks and quantifying changes, the Nature of Change analysis (NoC) will address the relationship occurring between stressors and response indicators and indices through time. Thus, the analysis will consider individual PMPs. For example, the response of the ecosystem to atmospheric inputs can be evaluated using different indicators, both biological (crown condition, increments, vegetation dynamics) and chemical (changes in soil and soil solution chemistry, stream flow chemistry, foliar chemistry). The simplest example is something like the regression between the (exceedance of) $\mathrm{N}$ deposition and the foliar concentration of $\mathrm{N}$ through time. As the time series increases and more cases become available, new predictors can be added to the model, with an evolution towards multiple regression. There are many exposure/predictors and response indicators/variables, and the choice of which to use will be made according to the time series availability and specific questions that the collection of data and the other two analyses (RA and $\mathrm{S} \& \mathrm{C})$ will raise. This analysis will be used to integrate the data from individual PMPs through time, and it will take time to collect a sufficient number of cases to allow proper correlation (Tabs 2, 3).

All the above analyses can be performed independently, although it is easy to recognize connections between them: for example, risk analysis may identify those plots expected to be sensitive to acidification and/or eutrophication, S\&C may provide quantitative estimation of the changes occurring in those ecosystems, and NoC can identify relationships between the observed changes in stressors and response variables (e.g., number of nitrophilous species and deposition of N-compounds).

\subsection{Indicators and indices}

The number of indicators and indices adopted at a given PMP defines the intensity level of monitoring. As reported by Hunsaker (1993), an indicator is a characteristic or an entity that can be measured or estimated in order to assess the status and trend of the target environmental resource. In the context of the CONECOFOR program, the forest is the target resource and trees, soil, ground vegetation, atmosphere are all possible indicators. However, an indicator can be measured for different characteristics: for example the atmosphere can be measured in relation to its chemical (e.g. ozone) and physical (e.g. solar radiation) characteristics. Therefore, an index can be defined as a characteristic 
Tab. 4. Number of variables (number of mandatory indicators) according to the intensity level of monitoring. (a): considered defoliation, discoloration only; (b): for each of two age classes; (c): for each soil layer; (d): for each species and layer; (e): for each open field, throughfall and stemflow (when measured); (f): open field and under canopy.

\begin{tabular}{ccc}
\hline Core surveys & + deposition & + meteo \\
\hline Crown condition: $2(\mathrm{a})$ & Deposition: $12(\mathrm{e})$ & meteo: 6 (f) \\
Foliar condition: 7 (b) & Gases: 3 & \\
Soil condition: 14 (c) & Soil solution: 8 & \\
Ground vegetation: 1 (d) & & 6 \\
Tree growth: 1 & 23 & 54 \\
Total: 25 & 48 & \\
Grand total: 25 & & \\
\hline
\end{tabular}

Tab. 5. Number of PMPs in Italy according to the species and to the surveys. Core surveys: crown condition, soil condition, foliar condition, growth and yield, ground vegetation. In brackets: number of plots inclusive of those selected/incorporated in 1999 and/or not operational yet.

\begin{tabular}{|c|c|c|c|c|c|}
\hline \multirow[t]{2}{*}{ Main species } & \multicolumn{5}{|c|}{ Number of plots } \\
\hline & Total & $\begin{array}{l}\text { with core } \\
\text { surveys }\end{array}$ & with ozone & with deposition & with meteo \\
\hline Beech & $7(10)$ & $7(10)$ & 7 & 6 & 2 \\
\hline Norway spruce & $4(5)$ & $4(5)$ & 4 & 3 & 4 \\
\hline Turkey oak & 4 & 4 & 4 & 2 & 1 \\
\hline Holm oak & $2(3)$ & $2(3)$ & 2 & 1 & 1 \\
\hline European oak & 2 & 2 & 2 & 1 & 1 \\
\hline
\end{tabular}

that describes the status of a given indicator (Ferretti 1997). Accordingly, ozone concentration is here considered as an index of the chemical condition of the atmosphere, and solar radiation as an index of the physical condition. The various papers in this issue of the journal can easily provide an idea as to the indicators and indices adopted by the monitoring program. Taking into account the above definitions, indicators and indices can be classified in relation to the compartment of the ecosystem they are related to (biological, chemical, physical) or their role (e.g. stressor, response).

\subsection{Variables and cases}

The whole I\&C system is strongly limited by the unfavourable ratio between variables (many) and cases (few) (Ferretti 2000c) (Tabs 4, 5). A value of 4-5 is considered the minimum acceptable ratio between cases and variables in multivariate statistics. It is therefore important to define variables and cases explicitly. Within the framework of the I\&C evaluation system a "variable" is a quantitative expression (either measured or calculated) of the index describing the status of a given indicator at a given PMP. The variables are expressed in terms of statistical descriptors (sum, mean, maximum...): examples can be the deposition $\left(\mathrm{kg} \mathrm{ha}^{-1}\right)$ of $\mathrm{N}_{-} \mathrm{NH}_{4}$, the median crown transparency, the maximum $\mathrm{O}_{3}$ concentration, the Shannon index, and so on. On the other hand, a "case" is an individual PMP at an individual year: for example PMP CAL1 (Calabria 1) at year 1998 is one case. Deposition of $\mathrm{N}_{-} \mathrm{NH}_{4}$ at PMP CAL1 at years 1998, 1999, 2000 is 1 variable:3 cases ratio. As for many analyses of ecological trends, there is some risk in this approach due to the temporal depend- ence of the data, which may introduce some disturbance in the data series, and to the multicollinearity of the data (e.g. $\mathrm{N}$ and $\mathrm{N} / \mathrm{Mg}$ ratio in the foliage) which violates the assumption of independency between variables. The latter especially will be considered when attempting to select the indices to be used as response-predictors in the model.

\subsection{Data availability, data quality, evaluation levels, time windows}

The basic requirement of integrated analysis is to have high quality (i.e. consistent, precise, complete) data sets (Ferretti et al. 2000b). Details on each of these issues are given by Ferretti \& Nibbi (2000). In addition, the timing and the spatial allocation of the various investigations cause problems for data aggregation (Ferretti 2000c). For example, not all surveys are carried out at all PMPs, nor do all the surveys start at the same time, nor do they have similar sampling regimes (Ferretti et al. 2000b). These facts have clear effects on the possibility of spatial and temporal aggregation of available data. To deal with this problem, different evaluation levels and time windows have been suggested. The "evaluation level" (EL) is defined by the investigations carried out at the PMPs: three major EL levels are considered, namely EL1 (which includes the PMPs where all the core surveys are carried out), EL2 (PMPs with core surveys + deposition) and EL3 (core surveys + deposition + meteorological measurements). Details of ELs are given by Ferretti (2000c).

The "time window" is defined taking into account the sampling regimes and/or data aggregation of the different investigations, namely 1 year (crown, ground 
vegetation, ozone, deposition, meteo), 2 years (foliage chemistry), 5 years (growth) and 10 years (soil). These different time schedules imply that different data can be available for the analysis over a given time window, and this is particularly relevant for the $\mathrm{S} \& \mathrm{C}$. Details on time windows are given by Ferretti (2000c).

\subsection{Data aggregation}

The aggregation of data will vary in relation to data availability (see above) and the analysis of concern. For RA, PMPs will be investigated individually since the aim is to identify the condition of risk for any of them. The same will be done for the NoC analysis, where the response of individual PMPs to a given stressor is of interest. The S\&C analysis will require a different aggregation of data in order to cope with the unfavourable ratio between cases and variables. For the S\&C, PMPs will be grouped according to the most important species (e. g.: beech, Norway spruce, Turkey oak and holm oak) and this will improve the chances for multivariate statistics: for example, beech PMPs will generate 78 cases by 2010 , thus supporting 15 variables to be used simultaneously in multivariate analysis (Tab. 3). As is obvious from table 3 , species with few plots, like Turkey oak and holm oak, will be difficult to investigate with multivariate statistics unless the time series becomes very long. This reflects again some basic problems with the design of the whole monitoring program where the problems associated with data analysis are not adequately considered.

\subsection{Evaluation process}

The previous sections may have provided an idea of the complex system within which the I\&C evaluations will work. The full process will require some time (Ferretti 2000c), but this does not mean that results will be not available for dozens of years. This is because the nature of the I\&C allows different kinds of analysis to be undertaken simultaneously. For example, RA for the identification of risks attributable to ozone can be undertaken as soon as five years of ozone data are available for the CONECOFOR PMPs (year 2000). Proper assessment of risks due to deposition will be addressed after five years of deposition data have been collected (year 2002), and so on. At the same time, the continuous collection of data will allow a first run of the S\&C for beech PMPs by the year 2005. Thus, the I\&C system should be seen as a process where different kinds of analysis are undertaken according to the availability of data and/or expressed needs and priorities.

\section{FIRST RESULTS}

Some first results obtained by combining data from different investigations are reported below to show the potential effects of a few stressor categories among those measured at the Italian PMPs and to demonstrate the value of the $\mathrm{S} \& \mathrm{C}$ analysis.

\subsection{Acidic and nitrogen deposition}

Low soil pH (Alianiello et al. 2000) coupled with relatively high deposition rates (Mosello \& Marchetto 2000) occurs in some plots (namely EMI1, PIE1) (Fig. 3 ). As an example, in figure 4 sulphur and nitrogen throughfall deposition for 1999 is plotted on a diagram showing the relevant critical load (CL) function based on the $5^{\text {th }}$, the $50^{\text {th }}$ and the $95^{\text {th }} \mathrm{CL}$ values estimated for Italy (Posch et al. 1999). Figure 4 suggests that deposition rates never exceed the $95^{\text {th }}$ and $50^{\text {th }}$ percentile critical load function, i.e. the function that identified protective values for the less sensitive ecosystems. On the other hand, the $5^{\text {th }}$ percentile CL function is frequently exceeded by 1999 deposition loads, thus suggesting that the most sensitive ecosystems may experience deposition rates exceeding their carrying capacity. However, the actual sensitivity of the PMPs (which differ in many characteristics) must be known in detail before any kind of statement can be made with certainty. For example, table 6 reports estimated CL values for acidity for the $1 \times 1 \mathrm{~km}$ cell within which the PMPs are located and the deposition rates actually measured at the PMPs (Posch et al. 1999; Buffoni, pers. com.). Apparently, PIE1 is confirmed as receiving exceeding acidifying compounds, while the situation is more doubtful for EMI1, where sensitivity to acidification seems to be much less. On the other hand, acidic deposition seems to exceed CL at TRE1, thus suggesting a potential impact even at low deposition rates. Thus, future work in this direction is needed to build up site-specific critical load functions.

In figure 5 the critical load functions for nutrient $\mathrm{N}$ $\left(5^{\text {th }}, 50^{\text {th }}\right.$ and $95^{\text {th }}$ percentile) are reported together with the deposition rates for each individual PMP. Both table 6 and figure 5 suggest that many PMPs may be at risk due to excessive $\mathrm{N}$ deposition. As an example, figure 6 reports the mean $\mathrm{N}$ concentration (1995-1999 period, Matteucci et al. 2000) in beech leaves at the various PMPs with beech as the main species plotted against the estimated exceedance of nutrient $\mathrm{N}$. While the various PMPs differ in many characteristics (e.g. Fabbio \& Amorini 2000; Campetella \& Canullo 2000), there is an apparently good relationship between $\mathrm{N}$ exceedance and foliar $\mathrm{N}\left(R^{2}: 0.85\right)$.

\subsection{Ozone}

Ozone has been repeatedly reported as a dangerous air pollutant for plants (e.g. Fuhrer et al. 1997; Grünhage et al. 2001) and symptoms attributable to ozone have been reported on spontaneous vegetation in Italy (e.g., Gravano et al. 1999; Cozzi et al. 2000). Mean weekly ozone concentration at the various PMPs fluctuated year by year, with 1997 and 1999 displaying the highest values (Buffoni \& Tita 2000). Potentially, there could be some risk due to ozone exposure (Fig. 7). For example, in 1999 mean weekly seasonal values were always above $40 \mathrm{ppb}$, suggesting that potentially high ozone doses will be available for the plants. 


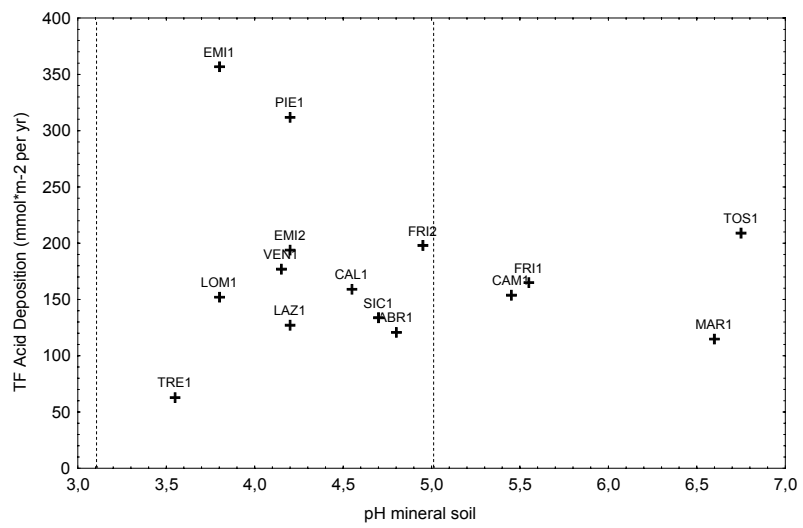

Fig. 3. Soil pH (mineral soil) and deposition of acidifying compounds in the throughfall in 1999 (Mosello \& Marchetto 2000). Dotted lines identify the range of $\mathrm{pH}$ values believed to be sensitive to changes induced by acidic deposition (Riek 1999). The codes of individual PMPs are reported in the graph.

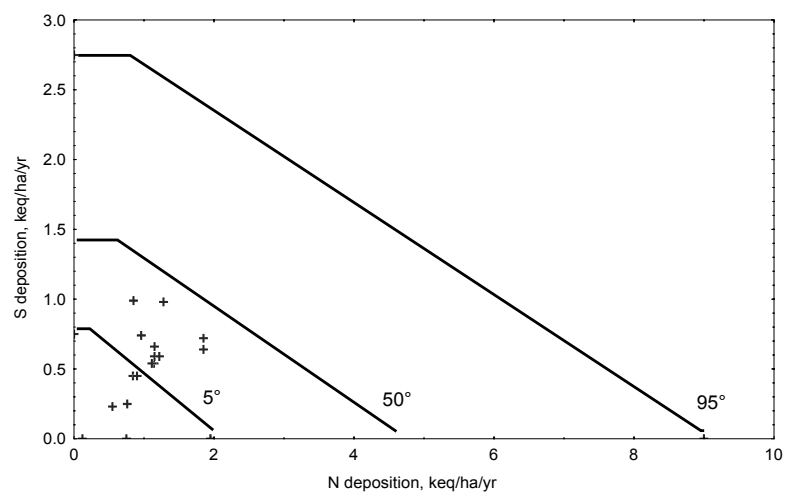

Fig. 4. Critical load functions for $S$ and acidifying $N$ at $5^{\text {th }}, 50^{\text {th }}$, and $95^{\text {th }}$ percentile for Italy (De Smet \& Posch 1999) in 1999 (Mosello \& Marchetto 2000). The $5^{\text {th }}$ percentile can be considered as the load above which effects are likely to occur in the most sensitive ecosystems; on the other hand, the $95^{\text {th }}$ percentile is the threshold above which the less sensitive ecosystems can be affected. Deposition rates at individual PMPs are reported.

Tab. 6. Critical loads for acidity and nitrogen estimated for the $1 \mathrm{x} 1 \mathrm{~km}$ grid cells where the PMPs are located (after: de Smet \& Posch 1999; Buffoni, pers. com.), actual deposition rates at the PMPs (1999) and potential exceedance. Data are reported in meq $\mathrm{m}^{-2} \mathrm{y}^{-1} .\left(^{*}\right) 1998$ data; $(* *)$ : only $\mathrm{N}-\mathrm{NH}_{3}$ and $\mathrm{N}-\mathrm{NH}_{4}$ considered.

\begin{tabular}{|c|c|c|c|c|c|c|}
\hline \multirow[b]{2}{*}{ PMP } & \multicolumn{2}{|c|}{ Critical Loads } & \multicolumn{2}{|c|}{ Deposition } & \multicolumn{2}{|c|}{ Exceedance } \\
\hline & Acidity & nutrient $\mathrm{N}$ & Acidity & $\mathrm{N}$ & Acidity & $\mathrm{N}$ \\
\hline ABR1 & $>2000$ & 578 & $1210\left(^{*}\right)$ & 760 & Unlikely & 182 \\
\hline BAS1 & 1388 & 928 & Not Measured & Not Measured & Unknown & Unknown \\
\hline CAL1 & $>2000$ & 883 & 1590 & 850 & Unlikely & $?$ \\
\hline CAM1 & $>2000$ & 815 & 1540 & 1110 & Unlikely & 295 \\
\hline EMI1 & $>2000$ & 600 & 3570 & 2205 & $?$ & 1605 \\
\hline EMI2 & $>2000$ & 750 & 1940 & 1150 & $?$ & 400 \\
\hline FRI1 & $>2000$ & 723 & 1650 & 1150 & Unlikely & 427 \\
\hline FRI2 & $>2000$ & 883 & 1980 & 1280 & $?$ & 397 \\
\hline LAZ1 & $>2000$ & 621 & 1270 & 840 & Unlikely & 219 \\
\hline LOM1 & 1575 & 404 & 1520 & 1140 & $?$ & 736 \\
\hline MAR1 & $>2000$ & 734 & 1150 & 900 & Unlikely & 166 \\
\hline PIE1 & 1929 & 922 & 3120 & 1850 & 1191 & 928 \\
\hline PUG1 & $>2000$ & 876 & Not Measured & Not Measured & Unknown & Unknown \\
\hline SAR1 & $>2000$ & 499 & Not Measured & Not Measured & Unknown & Unknown \\
\hline SIC1 & $>2000$ & 130 & 1340 & 960 & Unlikely & 830 \\
\hline TOS1 & $>2000$ & 622 & 2090 & $840(* *)$ & $?$ & 218 \\
\hline TRE1 & 505 & 791 & 630 & 550 & 125 & Unlikely \\
\hline UMB1 & $>2000$ & 906 & Not Measured & Not Measured & Unknown & Unknown \\
\hline VAL1 & $>2000$ & 407 & Not Measured & Not Measured & Unknown & Unknown \\
\hline VEN1 & $>2000$ & 975 & 1770 & 1220 & Unlikely & 245 \\
\hline
\end{tabular}




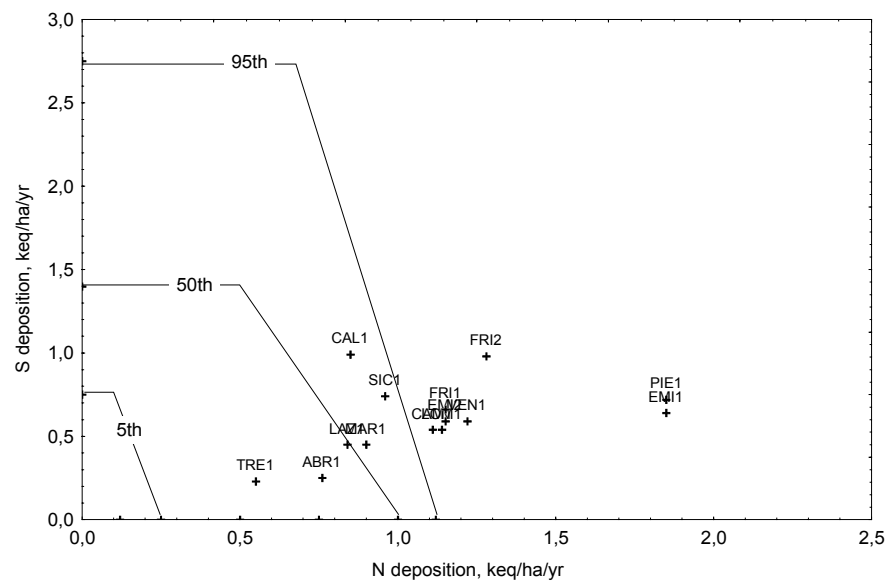

Fig. 5. Critical load functions for nutrient $N$ for Italy (De Smet \& Posch 1999) and throughfall deposition in 1999 (Mosello \& Marchetto 2000). The $5^{\text {th }}$ percentile can be considered as the load above which effects are likely to occur in the most sensitive ecosystems. On the other hand, the $95^{\text {th }}$ percentile is the threshold above which the less sensitive ecosystems can be affected. Deposition rates at individual PMPs are reported.

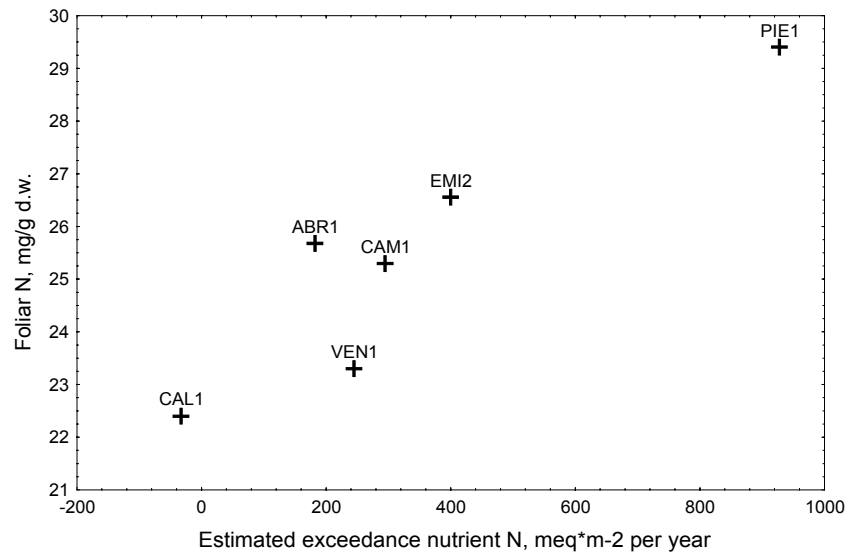

Fig. 6. Estimated exceedance of nutrient $\mathrm{N}$ at the beech PMPs plotted against the mean (1995-1999) foliar $\mathrm{N}$ concentration in beech leaves at the same PMP.

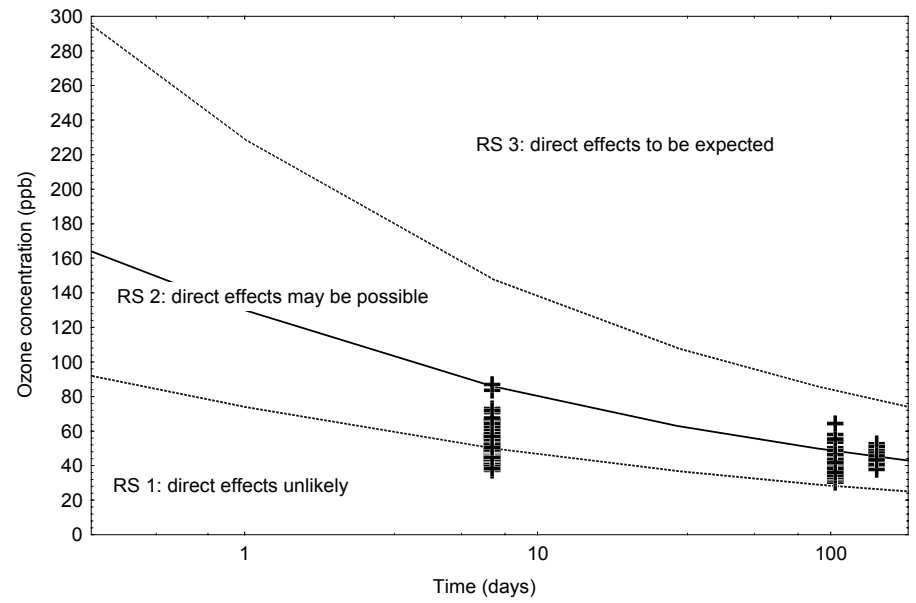

Fig. 7. Ozone concentration at individual PMPs for each individual year (1996, 1997, 1998 and 1999) plotted against different times of exposure: 7-days (maximum weekly average), 103 days (measurement period in 1996, 1997 and 1998) and 144 days (measurement period in 1999). The three different Risk Scenarios (RS) according to Grünhage et al. (2001) are reported. 


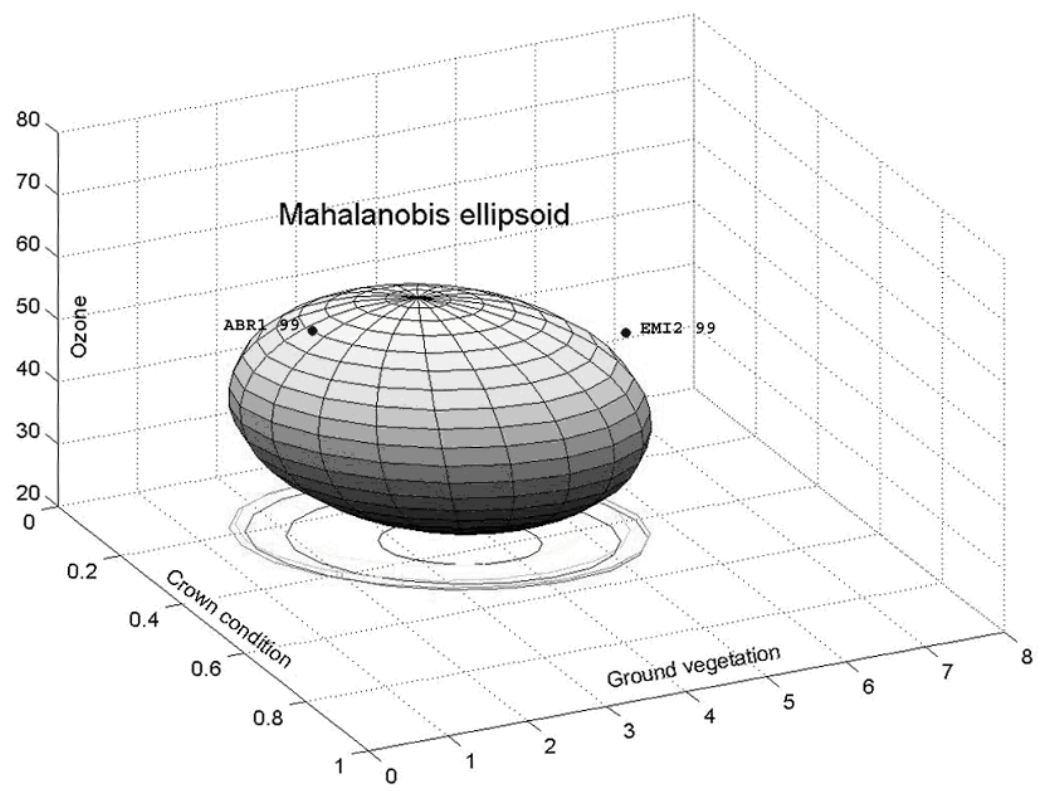

Fig. 8. 3D representation of the ellipsoid defining the status "close" to the mean and the cases which are "far", identified by the dots outside the ellipsoid.

However, the uptake of ozone by plants is controlled by many factors, with water stress being particularly important. For example, for similar levels of ozone concentration, the P-EPT (precipitation minus evapotraspiration) drought stress index varies between PMPs, suggesting that potentially different ozone fluxes may be occurring (Ferretti et al. 2000d). The P-EPT index does not account for soil moisture, so it has a number of limitations as an indicator of water stress (Amoriello \& Costantini 2000), yet it could give an idea as to how the potential for ozone uptake may be influenced. Ozone sensitivity is also dependent on species and age, with highly competitive species with a high growth rate being more sensitive (e.g. Mills et al. 2000). Ozone uptake depends also on tree age and within the PMPs of the CONECOFOR program there is a considerable variability in age. For example, the mean age of the dominant storey in beech PMPs varies from 40 to 110 years and this is another factor to be taken into account.

\subsection{Status and Changes}

The status and changes of 5 beech PMPs in relation to crown, ground vegetation and ozone are illustrated in figures 8 and 9. Figure 8 shows the ellipsoid (average Mahalanobis distance plus 1.5 times the standard deviation) and the condition, which are "far" from the mean distance. The same data are reported in the time dimension in figure 9. In 1999 both ABR1 and EMI2 fall outside the limit. However, the reasons behind these facts are probably different for the two PMPs (Ferretti et al. 2000d). At ABR1, 1999 was the year with the highest ozone concentration (52.7 ppb) compared to the previous years and the other PMPs (Buffoni \& Tita 2000). In
1999, this high concentration was coupled with a low value of Fisher alpha (Campetella \& Canullo 2000). High ozone concentration was recorded also at EMI2 and CAM1 in the same year. However, apart from its ozone concentration, EMI2 deviates markedly from the overall situation mainly because of the high values of Fisher alpha (Tab. 2). Campetella \& Canullo (pers. com.) suggests that this high value is due to an increase in the overall species diversity coupled with a simultaneous strong decrease in the number of individuals, which is nearly halved for both herbaceous and woody plants.

It is not easy to interpret the above data at the present time. The indices that caused deviation from the mean condition (ozone levels, ground vegetation diversity) seem to be particularly subject to short-term fluctuations. In this perspective, the observed deviations can be interpreted more in the sense of short-term "pulses" than as signals of an actual trend.

\section{CONCLUSIONS}

A summary of the achievements, problems and prospects emerging from the first phases of the I\&C analysis is provided by Ferretti et al. (2000a). Achievements include cooperation between scientists and program managers, improved knowledge about actual and potential data quality and precision, the value, the pros and the cons of indicator/indices of ecosystem status, formulation of explicit hypotheses and lines of research, identification of potential problems related to atmospheric input (mainly $\mathrm{N}$ deposition and ozone) and evidence of fluctuation of ecosystem status and its deviation from the "common" dynamics. 


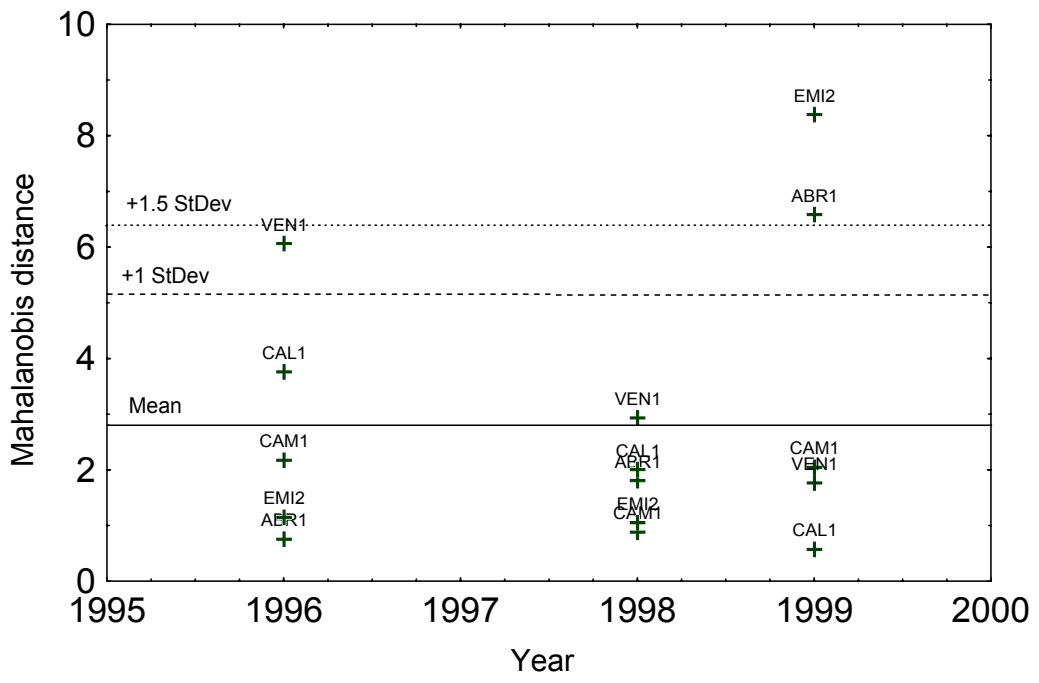

Fig. 9. Time trend of the values of the Mahalanobis distance for the beech PMPs. Mean distance and different limits (mean plus 1 time the s.d. and mean plus 1.5 times the s.d.) are reported.

Apart from the achievements, various problems can be identified with the I\&C evaluation system, particularly problems with the original design of the network, in terms of site selection, measurement priority and allocation, and intermittent monitoring.

The future prospects of the I\&C include two different activities: on one hand there will be a continuous update of the $\mathrm{I} \& \mathrm{C}$ data set, a review of the synthetic indices, a review of the entire I\&C system and its contribution to the overall program review, and the construction of an error model. On the other hand, the I\&C Task Force (2001) recently agreed on the nature of the next reports to be produced. Forthcoming reports (20022005) will be thematic and will deal with robust Risk Analysis (RA) for ozone, atmospheric deposition and meteorological stress. Vascular plant diversity and carbon stocks will be targeted over the same period. In the medium term (2006-2010) it will be possible to have a comprehensive $\mathrm{S} \& \mathrm{C}$ and $\mathrm{NoC}$ analysis and to update and review the RA.

\section{ACKNOWLEDGMENTS}

I am grateful to the program managers and all the members of the I\&C Task Force for their cooperation and support.

\section{REFERENCES}

Adams, D.C., J. Gurevitch \& M.W. Rosemberg. 1997. Resampling test for meta-analysis of ecological data. Ecology, 78: 1227-1283.

Alianiello, F., A. Biondi, C. Ferrari \& G. Mecella. 2000. Forest soil conditions at the Permanent Monitoring Plots in Italy. In: Ferretti M. (Ed.), Integrated and Combined (I\&C) evaluation of intensive monitoring of forest ecosystems in Italy - Concepts, methods and first results. Annali dell'Istituto Sperimentale per la Selvicoltura, Special Issue, 30: 99-104.
Amoriello, T. \& A. Costantini. 2000. Meteorological stress indices. In: Ferretti M. (Ed.), Integrated and Combined $(I \& C)$ evaluation of intensive monitoring of forest ecosystems in Italy - Concepts, methods and first results. Annali dell'Istituto Sperimentale per la Selvicoltura, Special Issue, 30: 129-134.

Bricker, O.P. \& M.A. Ruggiero. 1998. Toward a national program for monitoring environmental resources, Ecological Applications, 8: 326-329.

Buffoni, A. \& M. Tita. 2000. Ozone measurements by passive samplers at Italian forest sites. In: Ferretti M. (Ed.), Integrated and Combined (I\&C) evaluation of intensive monitoring of forest ecosystems in Italy - Concepts, methods and first results. Annali dell'Istituto Sperimentale per la Selvicoltura, Special Issue, 30: 121-127.

Campetella, G. \& R. Canullo. 2000. Plant biodiversity as an indicator of the biological status in forest ecosystems: community and population level indices. In: Ferretti M. (Ed.), Integrated and Combined (I\&C) evaluation of intensive monitoring of forest ecosystems in Italy - Concepts, methods and first results. Annali dell'Istituto Sperimentale per la Selvicoltura, Special Issue, 30: 73-79.

Chappelka, A. \& P. Freer-Smith. 1995. Predisposition of trees by air pollutants to low temperatures and moisture stress. Environmental Pollution, 87: 105-117.

Cozzi, A., M. Ferretti \& J.L. Innes. 2000. Sintomi fogliari attribuibili ad ozono sulla vegetazione spontanea in Valtellina. Monti e Boschi, 3-4: 42-49.

EC-UN/ECE. 1998. De Vries, W., G.J. Reinds, H.D. Deelstra, J.M. Klap \& E.M. Vel. Intensive Monitoring of Forest Ecosystems in Europe, 2000 Technical Report. EC, UN/ECE 1998, Brussels, Geneva: 193 pp.

Elzinga, C.L., D.W. Salzer, J.W. Willoughby \& J.P. Gibbs. 2001. Monitoring plant and animal population. Blackwell Science, Malden, Massachusetts, USA: $337 \mathrm{pp}$.

Fabbio, G. \& E. Amorini. 2000. Tree growth survey and increment assessment. Ferretti M. (Ed.), Integrated and Combined $(I \& C)$ evaluation of intensive monitoring of forest ecosystems in Italy - Concepts, methods and first results. Annali dell'Istituto Sperimentale per la Selvicoltura, Special Issue, 30: 81-89.

Ferretti, M. 1997. Forest health assessment and monitoring. Issues for consideration. Environmental Monitoring and Assessment, 48: 45-72. 
Ferretti M. (Ed.). 2000a. Integrated and Combined (I\&C) evaluation of intensive monitoring of forest ecosystems in Italy - Concepts, methods and first results. Annali dell'Istituto Sperimentale per la Selvicoltura, Special Issue, 30: $156 \mathrm{pp}$.

Ferretti, M. 2000b. An introduction to the integrated and combined (I\&C) evaluation system designed for the intensive monitoring of forest ecosystems in Italy. In: Ferretti M. (Ed.), Integrated and Combined $(I \& C)$ evaluation of intensive monitoring of forest ecosystems in Italy - Concepts, methods and first results. Annali dell'Istituto Sperimentale per la Selvicoltura, Special Issue, 30: 7-16.

Ferretti, M. 2000c. Spatial and temporal aggregation of the CONECOFOR data for I\&C analyses. In: Ferretti M. (Ed.), Integrated and Combined (I\&C) evaluation of intensive monitoring of forest ecosystems in Italy - Concepts, methods and first results. Annali dell'Istituto Sperimentale per la Selvicoltura, Special Issue, 30: 59-66.

Ferretti, M. \& R. Nibbi. 2000. Procedures to check availability, quality, and reliability of data collected at the CONECOFOR permanent monitoring plots. In: Ferretti M. (Ed.), Integrated and Combined (I\&C) evaluation of in tensive monitoring of forest ecosystems in Italy - Concepts, methods and first results. Annali dell'Istituto Sperimentale per la Selvicoltura, Special Issue, 30: 43-57.

Ferretti, M., F. Alianiello, S. Allavena, T. Amoriello, E. Amorini, F.A. Biondi, A. Buffoni, F. Bussotti, G. Campetella, R. Canullo, A. Costantini, A. Cutini, G. Fabbio, C. Ferrari, P. Giordano, E. Magnani, A. Marchetto, G. Matteucci, C. Mazzali, G. Mecella, R. Mosello, R. Nibbi, B. Petriccione, E. Pompei, F. Riguzzi, G. ScarasciaMugnozza, M. Tita. 2000a. The Integrated and Combined (I\&C) Evaluation System - Achievements, Problems and Perspectives. In: Ferretti M. (Ed.), Integrated and Combined (I\&C) evaluation of intensive monitoring of forest ecosystems in Italy - Concepts, methods and first results. Annali dell'Istituto Sperimentale per la Selvicoltura, Special Issue, 30: 151-156

Ferretti, M., F. Bussotti, P. Giordano, C. Mazzali \& R. Nibbi 2000b. Program CONECOFOR - Integrated and Combined (I\&C) evaluation of risk, status and changes of forest ecosystems. SISEF, Atti, 2: 435-440.

Ferretti, M., P. Giordano \& C. Mazzali. 2000c. Methods of analysis of the I\&C evaluation system. In: Ferretti M. (Ed.), Integrated and Combined (I\&C) evaluation of intensive monitoring of forest ecosystems in Italy - Concepts, methods and first results. Annali dell'Istituto Sperimentale per la Selvicoltura, Special Issue, 30: 33-42.

Ferretti, M., P. Giordano \& C. Mazzali. 2000d. Definitions of risk, status and changes in the Permanent Monitoring Plots in Italy - A preliminary attempt. In: Ferretti M. (Ed.), Integrated and Combined $(I \& C)$ evaluation of intensive monitoring of forest ecosystems in Italy - Concepts, methods and first results. Annali dell'Istituto Sperimentale per la Selvicoltura, Special Issue, 30: 135-149.

Field, J.G., K.R. Clarke \& R.M. Warwick. 1982. A practical strategy for analysing multispecies distribution patterns. Marine Ecol. Prog. Ser. 8: 37-52.

Fuhrer, J., L. Skärbi \& M.R. Ashmore. 1997. Critical levels for ozone effects on vegetation in Europe. Environmental Pollution, 97: 91-106.

Gravano, E., M. Ferretti, F. Bussotti \& P. Grossoni. 1999. Foliar symptoms and growth reduction of Ailanthus altissima Desf in an area with high ozone and acidic deposition in Italy. Water Air Soil Pollution, 116: 267-272.

Grünhage, L., G.H.M. Krause, B. Köllner, J. Bender, H.J.Weigel, H.-J. Jäger \& R. Guderian. 2001. A new fluxoriented concept to derive critical levels for ozone to protect vegetation. Environmental Pollution, 111: 355-362.
Gruppo di Esperti CONECOFOR-I\&C. 1998. Valutazione integrata e combinata $(I \& C)$ dei dati raccolti nelle aree permanenti di monitoraggio (APM) intensivo degli ecosistemi forestali in Italia. Rapporto 0. Internal report adoped at the meeting in Rome, 24 November 1998.

Hunsaker, C.T., R.L. Graham, G.W. Suter II, R.V. O'Neill, L.W. Barnthouse \& R.H. Gardner. 1990. Assessing ecological risk on a regional scale. Environmental Management, 14: 325-332.

Hunsaker, C.T. 1993. New concepts in environmental monitoring: the question of indicators, The Science of the Total Environment, Suppl.: 77-95.

Innes, J.L. 1994. Climatic sensitivity of temperate forests. Environmental Pollution, 83: 237-243.

Innes, J.L. 1998. Measuring Environmental Change. In: Peterson D.L., V.T. Parker (Eds), Ecological scale - Theory and Application. Columbia University Press: 429-457.

Innes, J.L., S. Ghosh \& A. Schwytzer. 1996. A method for the identification of trees with unusually colored foliage. Can. J. For. Res., 26: 1548-1555.

Johnson, A.R. 1988. Diagnostic variables as predictors of ecological risk. Environmental Management, 12: 512-523.

Kleemola, S. \& M. Forsius (Eds). 2000. International Cooperative Program on Integrated Monitoring of Air Pollutant Effects on Ecosystems. 9th Annual Report. Finnish Environment Institute, Helsinki. The Finnish Environment 427: $63 \mathrm{p}$

Legendre, P. \& L. Legendre. 1998. Numerical Ecology. $2^{\text {nd }}$ English Edition. Elsevier, Amsterdam: 853 pp.

Lundquist, J.E. \& J.S. Beatty. 1999. A conceptual model for defining and assessing condition of forest stands. Environmental Management, 23: 519-525.

Matteucci, G., E. Magnani, F. Riguzzi \& G. Scarascia Mugnozza. 2000. Possible indicators for the status and changes of Permanent Monitoring Plots derived from leaves and needles analysis. In: Ferretti M. (Ed.), Integrated and Combined (I\&C) evaluation of intensive monitoring of forest ecosystems in Italy - Concepts, methods and first results. Annali dell'Istituto Sperimentale per la Selvicoltura, Special Issue, 30: 105-116.

Mills, G., F. Hayes, A. Buse \& B. Reynolds. 2000. Air pollution and vegetation. UN/ECE ICP Vegetation. Annual Report 1999/2000. Centre for Ecology and Hydrology: 48 pp.

Mosello, R. \& A. Marchetto. 2000. Atmospheric Deposition and Streamflow Chemistry at the Permanent Monitoring Plots of the CONECOFOR program In: Ferretti M. (Ed.), Integrated and Combined (I\&C) evaluation of intensive monitoring of forest ecosystems in Italy - Concepts, methods and first results. Annali dell'Istituto Sperimentale per la Selvicoltura, Special Issue, 30: 117-120.

Posch, M., P.A.M. de Smet, J.-P. Hettelingh \& R. J. Downing. 1999. Calculation and mapping of critical thresholds in Europe. RIVM Report No. 259101009: 165 pp.

Power, M. \& S.M. Adams (Eds). 1997. Perspective of the scientific community on the status of ecological risk assessment. Environmental Management, 21: 803-830.

Skjelvåle, B.L. \& M.J. Ulstein 1998. Summary of the nine year report from the ICP-Waters Program. Published by the Norwegian Institute for Water Research (NIVA): $22 \mathrm{pp}$.

Spellerberg, I.F. 1994. Monitoring ecological change. Cambridge University Press: 334 pp.

Suter II, G.W. 1990. Endpoints for regional Risk Assessment. Environmental Management, 14: 9-23.

Task Force of Integrated and Combined evaluation. 2001. Il sistema di valutazione integrata e combinata nel periodo 2001-2005. Documento strategico: 9 pp.

Vaughan, H., T. Brydges, A. Fenech \& A. Lumb. 2001. Monitoring long-term ecological changes through the ecological monitoring and assessment network. Environmental Monitoring and Assessment, 67: 3-28. 